\title{
Rusty Pipe Syndrome: A Benign Cause of Altered Breast Milk Color in Lactating Mothers
}

\author{
Anil Kallesh ${ }^{1}$, Sushma Nangia ${ }^{1}$, Murugesan Ambalakkuthan ${ }^{1}$, Ravi Teja ${ }^{2}$ and Rimesh Pal ${ }^{2}$ \\ ${ }^{1}$ Department of Neonatology, Lady Hardinge Medical College, India \\ ${ }^{2}$ Department of Endocrinology, Post Graduate Institute of Medical Education and Research, India
}

Submission: December 14, 2019; Published: January 06, 2020

*Corresponding author: Sushma Nangia, Department of Neonatology, Lady Hardinge Medical College, New Delhi, India Anil Kallesh, Department of Neonatology, Lady Hardinge Medical College, New Delhi, India

\begin{abstract}
Altered breast milk color or a frank bloody discharge in a lactating mother calls for anxiety and cessation of breast feeding to the neonate. Etiology constitutes multitude of benign and malignant causes. Here we present a case of term neonate born to a primigravida mother by vaginal delivery with mother complaining of altered breast milk color on first couple of days of lactation. Mother was apprehensive to feed her milk to the baby. Local breast examination of mother was normal and breast ultrasound did not reveal any benign or malignant lesions. Breast feeding was continued after proper counselling of mother and the family members about the benign nature of her breast discharge. Mother's milk production increased by day 2 and 3 and altered color of breast milk decreased gradually and cleared completely by day 4 . After ruling out other benign and malignant causes, Rusty pipe syndrome was kept as the diagnosis. Rusty pipe syndrome is a common but under reported benign condition causing bloody or rusty colored breast discharge in Primi lactating mothers in the initial few days after delivery. Careful local breast examination and ultrasound imaging is required to rule out other causes; if the bloody discharge persists for more than a week, further investigation is warranted. A good lactational counselling and continued breastfeeding is required to alleviate the anxiety in the lactating mothers.
\end{abstract}

Keywords: Rusty-pipe syndrome; Breast discharge; Lactating mothers; Primigravida

\section{Introduction}

The occurrence of bloody discharge in a lactating mother not only calls for anxiety in the mother but also opens the door for many benign and malignant differentials for the above condition. It also can cause cessation of breast feeding for the newborn infant. Adequate counselling of the mother and family members and proper clinical evaluation of the mother for possible benign and malignant conditions not only alleviates the anxiety but also helps in sustaining breast feeding in such situations [1]. Often these mothers are subjected to extensive investigations, both non-invasive and invasive. Herein, we report a Primi lactating mother presenting with bloody discharge from both nipples after delivery. Careful history and evaluation revealed it to be a benign but uncommon condition called Rusty pipe syndrome. Bloody discharge slowly disappeared in $3-4$ days and breastfeeding was continued without any cessation.

\section{Case Report}

A term $2.45 \mathrm{~kg}$ female baby was born by normal vaginal delivery to a 23-year-old primigravida mother. The baby cried immediately after birth and Apgar scores were 8 and 9 at 1 and 5 minutes, respectively. After routine care, breastfeeding was started within the first hour of birth. After few breast feeds, due to improper latching at breast by the baby, expressed breast milk was attempted. During hand expression of breast milk, mother noticed brownish coloured fluid coming out from both the breasts (Figure 1). Mother was anxious about feeding it to her baby. It was a painless discharge with no history of trauma to the breast, fever or bleeding from any other sites. On examination, the mother was in good health. Examination of the breasts revealed no evidence of breast engorgement. Nipples were healthy with no cracks, ulcers, tenderness or any underlying palpable lump. Ultrasound examination of bilateral breasts was normal. Having ruled out all common causes, she was diagnosed as having Rusty pipe syndrome. Mother and her family members were counselled about the benign nature of her condition and breast feeding was continued. Over next 2-3 days, the brownish colour of breast milk changed gradually and disappeared completely establishing a normal breast milk colour by day 4 of delivery (Figure 2). There 
was no recurrence of symptoms. Baby was discharged on exclusive breast feeds. At 6 weeks follow-up, baby is on exclusive breast feeds and gaining weight adequately.

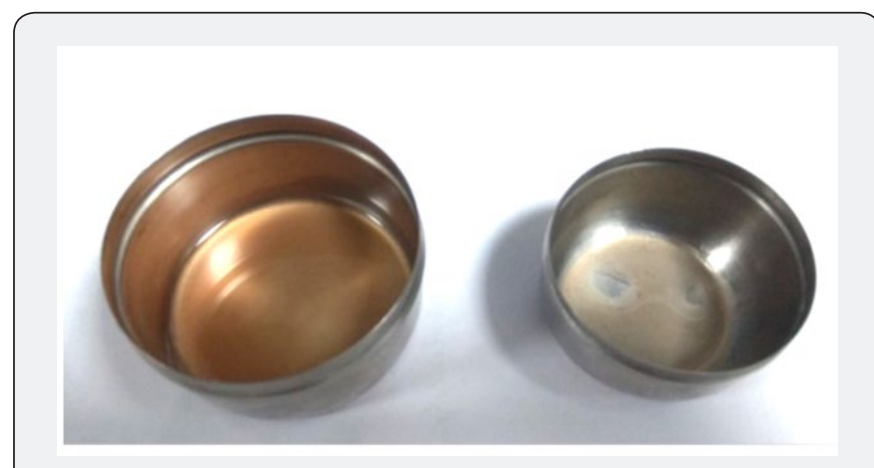

Figure 1: Rusty brown coloured colostrum expressed from both breast on day 1 after delivery.

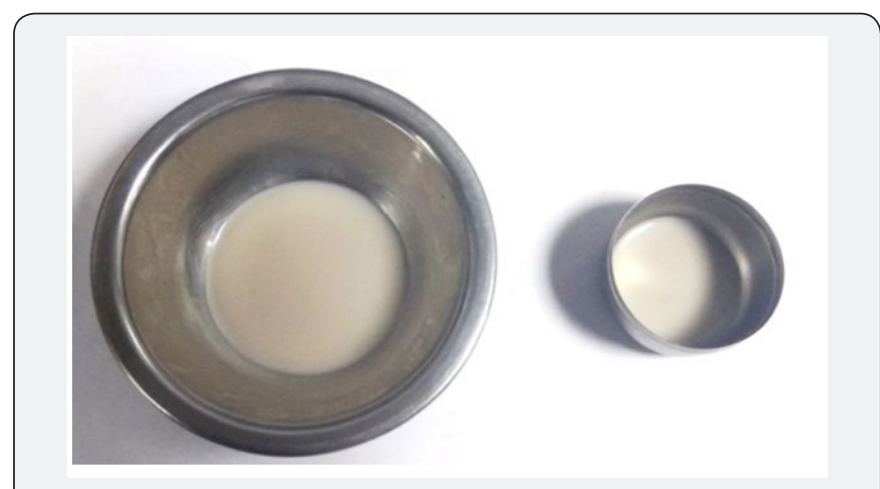

Figure 2: Clearing of brownish color fluid and expression of normal colored breast milk on day 4 after delivery.

\section{Discussion}

A bloody or serosanguineous breast discharge in a lactating mother can occur due to variety of common causes related to lactation, some are benign such as cracked nipples, mastitis, trauma or vascular engorgement and others are more serious breast conditions like ductal papilloma and fibrocystic disease [2]. Irrespective of the cause, the presentation of bloody discharge from breast is of great concern to both gynaecologist and neonatologist as it brings great anxiety in the lactating mothers directly impacting on the neonate's health and nutrition as breastfeeding is suddenly stopped. Such situation calls for careful history and proper clinical examination of the affected breast and ultrasound imaging to arrive at a proper diagnosis and management. A thorough knowledge of presentation of varying benign and malignant breast lesions is essential to arrive at diagnosis and avoid unnecessary investigations. The commoner and benign conditions listed earlier are painful and can be unilateral or bilateral and can be easily picked up by clinical examination of nipple area of the affected breast. Ductal papilloma is the most common cause of spontaneous unilateral bloody nipple discharge among all women $[2,3]$. The bleeding is painless and usually not associated with a palpable lesion. Fibrocystic disease, another commoner disease in childbearing age women shows areas of lumpiness and associated mastalgia. Frank bloody milk can also be due to another uncommon condition termed as 'Rusty pipe syndrome'. It is a painless condition and may go unnoticed unless the mother is expressing the milk or the infant vomits out blood, which tests positive for adult haemoglobin (Apt test) $[1,4,5]$. The bloody discharge from the breast is usually bilateral but may be unilateral to begin with. Most cases begin at birth or in early lactation period, but it may start in mid and later period of pregnancy as well. The exact incidence is not known as this condition is missed in many mothers and is diagnosed in only those mothers who express their milk for their neonates who are fed with expressed breast milk in neonatal intensive care units or nurseries. The etiopathogenesis is due to increased vascularization of rapidly developing alveolae in breasts during later half of pregnancy with delicate network of capillaries. These delicate and overgrown capillaries rupture easily and result in blood staining of breast secretion. It is commonly seen in primigravida mothers and is usually associated with nipple exercises like Hoffman's procedure, which is often recommended for flat or inverted nipples [6,7]. In the index case, bloody or rusty discharge developed on day 1 of birth of the baby; physical examination and breast imaging were normal and there was spontaenous clearing of bloody discharge by 3rd to 4 th day of lactation. This prompted the diagnosis of Rusty pipe syndrome. Since the condition resolved within few days, we did not subject the mother to further investigations. We encouraged mother to continue breastfeeding the baby and counselled about the benign nature of the condition and that the rust coloured milk produced in such situation is not harmful for the baby. Rusty pipe syndrome is a self-limited condition and, in most cases, bloody discharge clear within 3 to 7 days of onset of lactation. Nipple manipulation should be strrongly discouraged. If the infant tolerates milk, breast feeding can continue during this period. The mother should be evaluated further if the bloody discharge persists for more than one week. Since this benign condition is not commonly known to all clinicians and general public, we thought of discussing this common yet under reported phenomenon.

\section{References}

1. Murad TM, Contesso G, Mouriesse H (1982) Nipple discharge from the breast. Ann Surg 195(3): 259-264.

2. Gioffre Florio M, Manganaro T, Pollicino A, Scarfo P, Micali B (1999) Surgical approach to nipple discharge: a ten-year experience. J Surg Oncol 71(4): 235-238.

3. Virdi VS, Goraya JS, Khadwal A (2001) Rusty-pipe syndrome. Indian Pediatr 38(8): 931-932.

4. Silva JR, Carvalho R, Maia C, Osorio M, Barbosa M (2014) Rusty pipe syndrome, a cause of bloody nipple discharge: case report. Breastfeed Med 9(8): 411-412.

5. Faridi MMA, Dewan P, Batra P (2013) Rusty pipe syndrome: counselling a key intervention. Breastfeed Rev 21(3): 27-30.

6. Clark DL, Rudert C, Mangasaryan N (2011) Breastfeeding: a priority for UNICEF. Breastfeed Med 6: 349-351. 
7. Bergmann RL, Bergmann KE, von Weizsacker K, Berns M, Henrich W, et al. (2014) Breastfeeding is natural but not always easy: intervention for

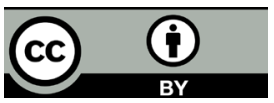

This work is licensed under Creative Commons Attribution 4.0 Licens

DOI: 10.19080/AJPN.2020.08.555800 common medical problems of breastfeeding mothers - a review of the scientific evidence. J Perinat Med 42(1): 9-18.

\section{Your next submission with Juniper Publishers} will reach you the below assets

- Quality Editorial service

- Swift Peer Review

- Reprints availability

- E-prints Service

- Manuscript Podcast for convenient understanding

- Global attainment for your research

- Manuscript accessibility in different formats

( Pdf, E-pub, Full Text, Audio)

- Unceasing customer service

Track the below URL for one-step submission

https://juniperpublishers.com/online-submission.php 